\title{
The Entrepreneurial Student's Experience Journey Through Engineering Education
}

\author{
https://doi.org/10.3991/ijep.v9i4.10216 \\ Mario Fallast ${ }^{(凶)}$, Stefan Vorbach \\ Graz University of Technology, Graz, Austria \\ mario.fallastetugraz.at
}

\begin{abstract}
The goal of this paper is to present a new perspective on how to design entrepreneurial education in the broader sense as part of engineering education. The perspective of the student ("customer") is put into the center of attention by applying the method of "customer journey mapping," which is widely used in the field of marketing. It intends to raise awareness for a more holistic and customer-centric view of the entrepreneurship-related "customer experience."

The paper shows the limitations of existing tools and procedures and gives an outlook on possible tools to describe customer experience journey in education.
\end{abstract}

Keywords-Entrepreneurship education, entrepreneurial intention, experience design, customer journey

\section{Introduction}

Educating future entrepreneurs is increasingly requested from universities and higher education institutions. This includes the field of engineering education, with its high potential for start-up ideas. Students in general and engineering students in particular have been identified as promising candidates for entrepreneurship education [1]. However, entrepreneurship education is not widely offered in engineering education - nor it is described. The most successful ways to educate future entrepreneurs have not yet been identified, nor have the best approaches been established for releasing the entrepreneurial potential of engineering students, who are free to choose the career path of an entrepreneur.

\subsection{Situation analysis, context}

Designing engineering education curricula based on the necessary theoretical knowledge and practical skills is a widely accepted approach. However, when talking about "entrepreneurship," mindset and attitudes play essential roles. The overall influencing factors for a person's decision to start entrepreneurial activities or even become an entrepreneur have to be taken into account as well. Existing elements in curricular activities and providing access to knowledge seem to be only minor influencing fac- 
tors towards (or against) this decision. The possible measures to foster entrepreneurial intention and entrepreneurial self-efficacy are far more wide-ranging in scope than merely offering a set of university courses to teach the necessary skills to become an engineer.

\subsection{Objectives of the paper}

The mechanisms leading to the decisions by students to start a business themselves and become entrepreneurs have not yet been clarified. The goal of the paper is to contribute a tool towards a better understanding of what influences students in general, engineering students specifically, during their time spent under the influence of an educational institution. In this context, we present a new perspective on how to design entrepreneurial education for engineering students in the broader sense. It aims to support engineering educational institutions (colleges, universities) in observing and understanding what happens in this process and consequently to enable them to actively designing curricula together with the surrounding activities and initiatives to foster entrepreneurial intention.

In our approach, we apply the method of "customer journey mapping," which is widely used in the field of marketing, to put the perspective of the student ("customer") in the center of attention. This new focus raises awareness for a more holistic and customer-centric view on the entrepreneurship-related "customer experience." The paper encourages critical engagement with the existing elements in education and invites practitioners to take a closer look at the effect of events and incidents.

\section{Theoretical Background}

Two areas of research, "customer journeys" and "entrepreneurial education" historically evolved from the two very different fields of marketing and education.

Both are summarised in the following section in order to set the foundation for combining them:

\subsection{Entrepreneurial education}

In the course of a report produced for the European Commission [2] 20 case studies about innovative entrepreneurship education (EE) practices at European universities were collected and analysed: "When looking at the design, the objectives of entrepreneurship education are usually a combination of the development of theoretical knowledge and practical skills for entrepreneurial thinking and acting." It makes the further point that the academic literature summarises the impacts of EE as being still unclear and not well understood. In another meta-study with a total sample size of more than 35.000 individuals, after controlling for pre-education entrepreneurial intentions, the relationship between entrepreneurship education and post-education entrepreneurial intentions was found to be not significant [3]. Something else seems to be happening besides classical entrepreneurship education. 
In order for people to believe in themselves, it is necessary for them to experience sufficient success when using what they have learned [4]. One of the mechanisms that occupy a central role in the regulatory process between motivation and performance attainments works through the beliefs people have in their efficacy. [4] Entrepreneurial self-efficacy refers to a belief in one's ability to successfully perform the various roles and tasks of entrepreneurship [5].

The results of a study [6] underscore the importance of entrepreneurial selfefficacy as a critical component in understanding entrepreneurship interest and actual career choice. Perceived self-efficacy influences the belief people have in their capabilities to spark the motivation, cognitive resources, and the actions needed to exercise control over events in their lives [4]. The exact mechanisms involved in this are not clear yet:

Empirical studies on the effect of entrepreneurship education on the entrepreneurial self-efficacy and entrepreneurial intention of students show mixed results [3]. Souitaris et al [7] tested the effect of entrepreneurship programmes on entrepreneurial attitudes in order to find out whether entrepreneurship education stimulates and reinforces the intention to start a business. They also summarise psychological literature, where intention proved to be the best predictor of planned behavior. In summary, the study illustrated that entrepreneurship programmes are a source of trigger-events that inspire students (arouse emotions and change mindsets). Inspiration is the benefit that raises entrepreneurial attitudes and intentions. The study additionally suggests investigating what kinds of emotions are experienced after each of the various triggerevents during an entrepreneurship programme [7].

\subsection{Trigger events in entrepreneurship education}

Within our research, we wish to put a focus on these specific trigger-events. We assume that placing particular importance upon the detailed design of such trigger events - including the emotions that shall be generated - will affect the results of entrepreneurial education. The effects of certain trigger-events and their accumulation are already known to be important in other fields of research, e.g. marketing or service design. These affect the overall impression on a "customer" - essential for the survival of organisations depending on the customer's decision in a purchase process. Many organisations, therefore, consciously plan the sequence of events a customer is experiencing in a purchasing or service process. Many resources are used to provide customers with a consistent shopping experience - no matter which specific store you buy a product at or which call center agent is talking to a customer.

Customer journey mapping (CJM) is seen as a useful and increasingly popular strategic management tool to understand an organisation's customer experience. Both academics and practitioners value it for its usefulness for understanding organisation customer experience. [8] 


\subsection{Customer experience mapping}

Rosenbaum et al. [8] describe the approach of customer journey mapping as follows: It is a visual depiction of the sequence of events through which customers interact with a service organisation during an entire [purchase] process. These "events" are typically called touchpoints and are often accompanied by emotional indicators. Touchpoints occur whenever a customer "touches" an organisation, across multiple channels and at various points in time [9].

The literature, e.g. [9], extends the range of a customer journey to all activities and events related to the delivery of a service and highlights the perspective from which the process is seen in a customer journey: the customer's perspective. It is of importance and value to skillfully manage the entire journey and not only single touchpoints [10].

The customer journey is also described as one of the frameworks in the service design process, used to understand how customers behave during a journey, what they are feeling, and what their motivations and attitudes are during that journey [9].

An Analogy to institutions of higher education: We see a direct analogy to institutions of higher education: Students are seen as "customers". The institution of higher education is seen as a "service organisation". It can consciously design a series of activities - curricular as well as extracurricular activities. Single touchpoints are designed by the staff. The responsibility for an entire journey made by the students lies at the university management level. Compared to a typical purchase or service process in business, the design of a Higher Education Institution curriculum is a far more complicated process, often based on existing procedures. This applies when talking about the series of courses and their content, but gets even more complicated when one would include more "soft" factors like emotions, culture, mindsets, and beliefs of students. Some of the mentioned factors are definitely already part of daily routines but often as a result of given structures and unconsciously passed values and patterns of action.

An Analogy to extracurricular activities: When the literature [11] describes a growing tendency for outsourcing elements in the service delivery process, thus leaving the customer engaged with several complementary service providers, we can extend the analogy to extracurricular activities.

Many extracurricular activities like student clubs, formula student racing teams, and events are initiated and organised by the students themselves. However, university management has the opportunity to influence the visibility, success, and image of these activities by (not) supporting them in various ways. The allocation of financial or human resources to support or enable these activities is only one approach, to actively communicate the appreciation for such intrapreneurial activities, another one.

So even if extracurricular activities are not planned top-down by university management, it can influence them.

In summary, the literature [12] states that customer experience is often considered predominantly as an overall evaluation, which restricts the understanding of the key "moments of truth" between the customer and an organisation. 
We see an analogy with curriculum design, where the lowest level of detail in designing is usually a description of the taught content and objective of a course. Often, the intended effect of a course and its specific elements are not considered further.

The set of contacts between customers and organisations - customer journeys - are generally becoming more and more complex, which raises the need for focussing on the overall customer experience.

The same applies to institutes of higher education.

Customers now interact with organisations through an immense number of touchpoints in multiple channels and media, resulting in more complex customer journeys: Omni-channel management has become the new norm and firms are confronted with accelerating media and channel fragmentation [13].

Planned customer experience journeys: Even if a journey and its included elements are planned very well, during the execution of the service, the actual journey can differ significantly from the planned journey. When analysing planned and actual journeys, this deviation plays an important role. It is the basis for further improvement; discussing the deviations offers the opportunity to align expectations and reality.

The planning of customer journeys is already known in the literature as "service blueprinting", which describes what "an organisation plans for a customer. Touchpoints and journeys represent what happens from the customer's point of view" [9].

\section{The Customer Experience Journey}

Customer journey mapping or customer experience mapping are valuable tools for understanding and designing the interactions between single persons and an organisation.

We suggest the use of the customer journeys and customer experience mapping to analyse and map the journey of students during their time where institutions of higher education, directly and indirectly, influence them.

The literature review showed that the necessary tools are not described very well in the existing academic work. The analysis of customer experiences is widely used in marketing and support processes, and often performed within firms or by consultancy firms focussing on that field. There is very little literature available on how experiences of customers of higher education in general and entrepreneurial education specifically (could) resonate.

\subsection{The approach to customer experience journeys}

In general, the literature, e.g. [11] suggests a five-phase approach to analyse customer journeys. Figure 1 and 2 describe the five phases as follows: 


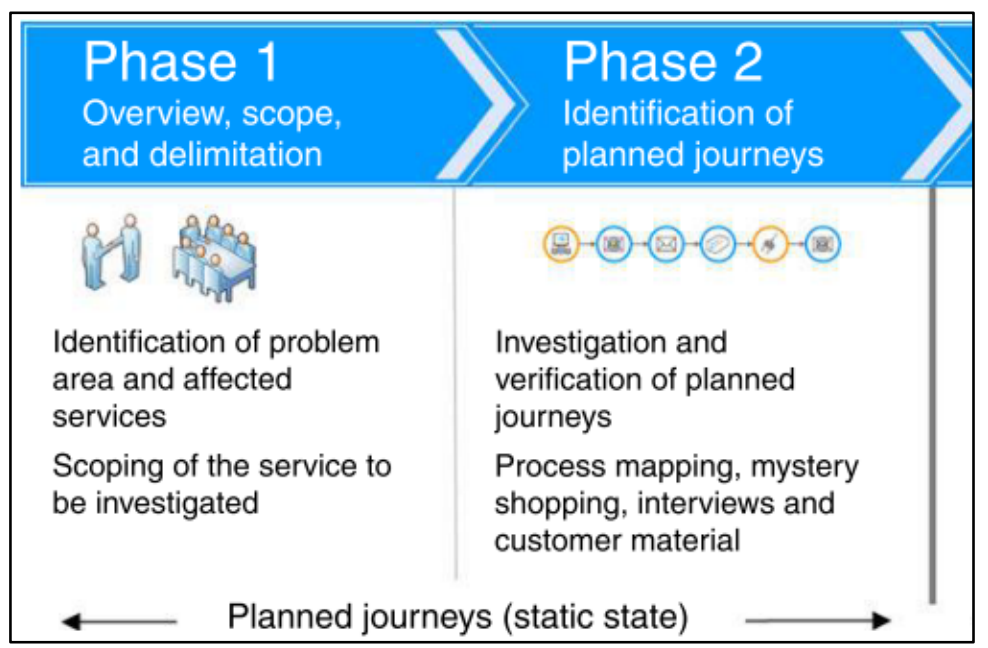

Fig. 1. The first two of five phases of the customer journey analysis according to [11].

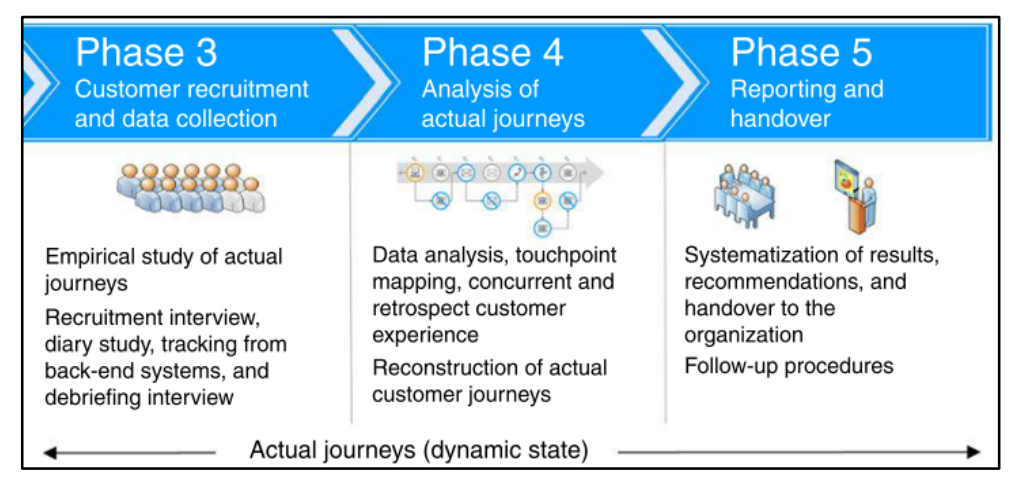

Fig. 2. Phase three to five of the customer journey analysis according to [11].

In the case of Graz University of Technology (TUG) - and this seems to be the case in most institutions of higher education - there is no "planned journey" within entrepreneurship education. Therefore, as a first step, we performed phase 3 (the empirical study of actual journeys) at the very beginning. We conducted a series of qualitative interviews at TUG to find out which experiences were the most influential ones. We used semi-structured interviews to find out which of these were recognized by entrepreneurs as being influential for their entrepreneurial intention.

It quickly became noticeable that some experiences, which had been thought to be crucial and supportive for students, in fact had very little impact ("failed touchpoints"), whereas others ("ad hoc" touchpoints), which were never intended by university management (but happened at university) had a significant influence on the entrepreneurial intentions of students. 
We also found that entrepreneurs often did not regard university courses in a traditional sense to be supportive of their entrepreneurial intention - in some cases, the courses were seen by university management to have highly positive impacts.

In some of these examples, the following situation occurred: The content of the course could be seen as supportive once the decision to become an entrepreneur was taken. However, at this specific phase of the study, the interest for it was not given at all. Even less, the contents had the potential to promote interest in the topic of entrepreneurship. Even if the course has a positive impact on the success rate of start-ups, at the same time it had a negative influence on the entrepreneurial intention of the students attending the course.

Other examples showed seemingly randomly occurring events - such as a supportive interaction with a professor - being very influential. The support of a professor or a respected person, in general, had a positive influence on entrepreneurial intention. The support given is in most cases not connected directly to a course. Courses are the occasions where contact between students and professors is established. However, more influencing discussions often happen outside curricular activities.

One of the few examples targeting the entrepreneurial intention is the course "Gruendungsgarage" (GG, "Founders' garage"), offered at Graz University of Technology (TUG)[14]. The GG course aims to offer an authentic entrepreneurship experience, as it guides start-ups from their first idea to a professional business that can stand on its own feet. The course exposes students to real-world start-up problems and opportunities and offers a model of how to effectively encourage entrepreneurship experience [15]. Gruendungsgarage offers entrepreneurs the support of university lecturers with expertise in entrepreneurship as well as an extensive network of experienced business professionals as mentors. The face-to-face interaction between students and the mentors is a crucial element of the course and allows for tailored support of individual students with their particular skills, beliefs, and limitations. All mentors are committed to supporting the students not only with their knowledge but inherently aim to increase their entrepreneurial intention.

Another example offered at TUG is the two-semester course "product innovation project". The aim of the "product innovation project" is to expand the high level of the students" academic education towards a more practical and "market-like" view.

Interdisciplinary and international teams of students work on a task given by an industrial sponsor. [16]

\subsection{Sample journey through a student's entrepreneurial education in the broader sense}

We wanted to find out in which university-related activities (curricular, extracurricular) students get in touch with entrepreneurship and how they perceive these touchpoints and specific elements thereof.

Hence, an empirical approach with qualitative interviews has been chosen in order to identify characteristics of entrepreneurship-related touchpoints. We set up a list of descriptive elements that were mentioned in the literature to prepare the semistructured interviews. On the one hand, these are intended to act as a guideline for the 
interviewer, and on the other hand, as a "checklist" to cover all fields of interest. In the first interviews we carried out in the preparation phase, we found that the interview partner tended not to mention certain elements of their own accord. For example, there was usually no description given about the emotions involved when describing a specific situation.

On the other hand, in one of the very first interviews, the interviewee mentioned descriptive elements, which were not prepared or mentioned in our interview guideline.

Figure 3 shows the first concept of a sample student's journey through entrepreneurial education in the broader sense. It includes university courses, but also touchpoints, which are not managed by the university. Touchpoints perceived as supportive to entrepreneurial intention were placed above the horizontal centerline, touchpoints decreasing entrepreneurial intention placed below.

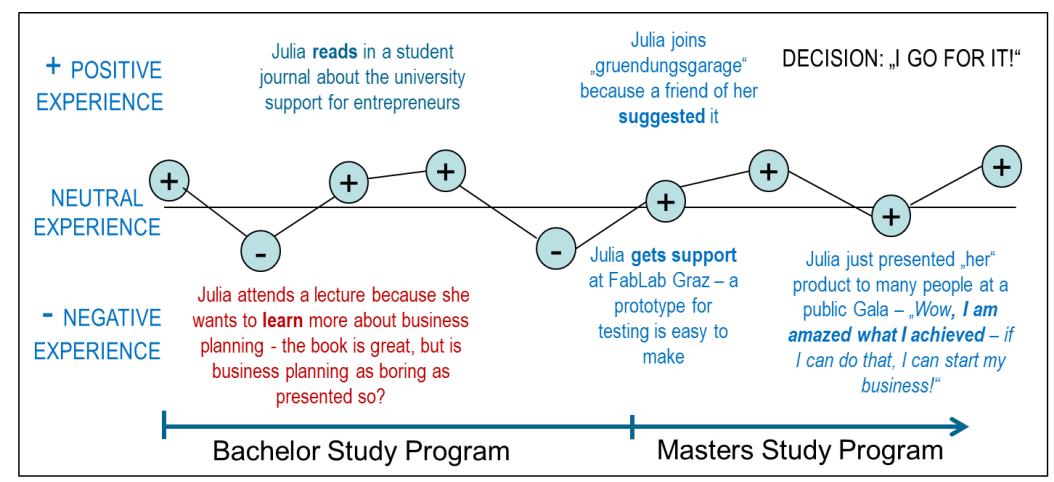

Fig. 3. A sample student's journey through entrepreneurial education.

\section{Outlook}

There are still limitations to the capability of existing tools to map and design customer experience journeys. The journey of students through the educational system is highly complex, even when it is filtered down to entrepreneurship-relevant topics.

It becomes evident that many entrepreneurship-relevant touchpoints occur unintended or unconsciously within curricular activities or occur outside the actual curriculum. It is highly suggested to analyse entrepreneurship education elements in engineering education in a broader context. The design of analytical tools is seen as a necessary step.

\section{$5 \quad$ References}

[1] P. Holzmann, E. Hartlieb, and M. Roth, "From Engineer to Entrepreneur - Entrepreneurship Education for Engineering Students: The Case of the Entrepreneurial Campus Vil- 
lach,” Int. J. Eng. Pedagog., vol. 8, no. 3, p. 28, 2018. https://doi.org/10.3991/ijep.v8i3. $\underline{7942}$

[2] S. Lilischkis, C. Volkmann, M. Gruenhagen, K. Bischoff, and B. Halbfas, "Supporting the Entrepreneurial Potential of Higher Education, Final Report," 2015.

[3] T. J. Bae, S. Qian, C. Miao, and J. O. Fiet, "The Relationship Between Entrepreneurship Education and Entrepreneurial Intentions: A Meta-Analytic Review," Entrep. Theory Pract., vol. 38, no. 2, pp. 217-254, 2014. https://doi.org/10.1111/etap.12095

[4] R. Wood and A. Bandura, "Social Cognitive Theory of Organizational Management University of New South Wales,” Acad. Manag. Rev., vol. 14, no. 3, pp. 361-384, 1989.

[5] C. C. Chen, P. G. Greene, and A. Crick, "Does entrepreneurial self-efficacy distinguish entrepreneurs from managers?," J. Bus. Ventur., vol. 13, no. 4, pp. 295-316, 1998. https://doi.org/10.1016/s0883-9026(97)00029-3

[6] F. WILSON, J. KICKUL, D. MARLINO, S. D. BARBOSA, and M. D. GRIFFITHS, "an Analysis of the Role of Gender and Self-Efficacy in Developing Female Entrepreneurial Interest and Behavior,” J. Dev. Entrep., vol. 14, no. 02, pp. 105-119, 2009. https://doi.org/ $\underline{10.1142 / \mathrm{s} 1084946709001247}$

[7] V. Souitaris, S. Zerbinati, and A. Al-Laham, "Do entrepreneurship programmes raise entrepreneurial intention of science and engineering students? The effect of learning, inspiration and resources," J. Bus. Ventur., vol. 22, no. 4, pp. 566-591, 2007. https://doi.org/10. 1016/j.jbusvent.2006.05.002

[8] M. S. Rosenbaum, M. L. Otalora, and G. C. Ramírez, "How to create a realistic customer journey map,” Bus. Horiz., vol. 60, no. 1, pp. 143-150, Jan. 2017. https://doi.org/10.1016/ j.bushor.2016.09.010

[9] L. G. Zomerdijk and C. A. Voss, "Service design for experience-centric services," J. Serv. Res., vol. 13, no. 1, pp. 67-82, 2010.

[10] A. Rawson, E. Duncan, and C. Jones, "The truth about customer experience," Harv. Bus. Rev., vol. 91, no. 9, 2013.

[11] R. Halvorsrud, K. Kvale, and A. Følstad, "Improving service quality through customer journey analysis," J. Serv. Theory Pract., vol. 26, no. 6, pp. 840-867, Nov. 2016. https://doi.org/10.1108/jstp-05-2015-0111

[12] A. Stein and B. Ramaseshan, "Towards the identification of customer experience touch point elements," J. Retail. Consum. Serv., vol. 30, pp. 8-19, 2016.

[13] K. N. . Lemon and P. C. Verhoef, "Understanding Customer Experience Throughout the Customer Journey,” J. Mark., vol. 80, no. 6, pp. 69-96, 2016. https://doi.org/10.1509/jm. $\underline{15.0420}$

[14] M. Glinik, "Gruendungsgarage - A Best-Practice Example of an Academic Start-up Accelerator," vol. 9, no. 3, pp. 33-43, 2019.

[15] S. Vorbach, "Lecturing Entrepreneurship at Graz University of Technology," no. September, pp. 54-61, 2017.

[16] M. T. T. Reinikainen and M. Fallast, "A platform for innovative entrepreneurship and European innovation education, experiences from PDP, PIP and FLPD,” Proc. 36th Eur. Soc. Eng. Educ. SEFI Conf. Qual. Assessment, Employab. Innov., no. November, 2008.

\section{Authors}

Mario Fallast has an interdisciplinary background as co-founder of a high-tech Start-up as well as a member of the Research and Technology House at Graz University of Technology, where he supports SME and founders in their collaboration with 
research institutions. He holds a diploma degree in mechanical engineering and business economics and is a $\mathrm{PhD}$ candidate at Graz University of Technology, passionate about releasing the entrepreneurial potential of students.

Stefan Vorbach is a Professor at the Institute of General Management and Organization at Graz University of Technology. He holds a diploma degree in mechanical engineering and business economics and a $\mathrm{PhD}$ in technical sciences, both from Graz University of Technology. His research concentrates on topics including: innovation and technology management, particularly business model innovation, strategic management, entrepreneurship and intrapreneurship.

Article submitted 2019-01-28. Resubmitted 2019-07-03. Final acceptance 2019-07-03. Final version published as submitted by the authors. 